\title{
The theory on the organization principles and Strategies of sunshine sports in Colleges and Universities
}

\author{
Gu XiuHua \\ Shanghai Second Polytechnic University \\ (email:gxiuhua@126.com)
}

\begin{abstract}
Studies have shown: Although development and great achievements have been made in the student sunlight sports in China, there are still many matters of principle which must pay more attention to and improve, such as: the understanding is not clear, the connotation is not grasped accurate, paying much attention on the form but lighting the result, the participation active of student is not high. The organization of sunlight sports activities must follow the law of sports, Improve the top-level design, highlight bright spot, form the characteristic, and the complete and close quality monitoring and evaluation system have to be established to make sure the organization of the activities more effective and scientific.
\end{abstract}

Keywords: colleges and universities; the sunlight sports; organizational principle; strategy

\section{论普通高校阳光体育运动的组织原则与策略 \\ 顾秀华 \\ 上海第二工业大学 \\ (email:gxiuhua@126.com)}

\begin{abstract}
摘要: 研究表明, 在我国学生阳光体育运动 开展取得巨大成效的同时, 也还存在诸如认 识不清晰、内涵把握不准确、重形式轻效果、 学生参与的积极性不高等许多原则性问题, 必须加以重视和改进。阳光体育活动的组织 必须遵循体育运动的规律，完善顶层设计， 突出亮点、形成特色, 并建立完整闭合的质 量监控及考核体系, 使活动的组织更加效性 和科学。
\end{abstract}

关键词: 普通高校; 阳光体育; 组织原则; 策 略

\section{1. 引言}

从2007年我国政府正式宣布启动“全国 亿万青少年阳光体育运动” 以来, 已经过去 了整整 5 个年头, 阳光体育运动已经在各级 各类学校得到了长足的发展, 据国家教委最
新公布的学生体质监测数据表明, 我国青少 年学生的体质健康水平正在逐步好转, 学生 各项身体素质逐年下滑的局面已经得到了 一定的遏制, 中共中央、国务院关于加强青 少年体育增强青少年体质的要求已经初见 成效。在阳光体育运动开展取得巨大成效的 同时, 我们也发现各级行政管理部门和许多 学校对阳光体育运动内涵的认识还不够清 晰, 对如何组织开展阳光体育运动缺乏有效 的抓手, 许多活动的组织违背了体育运动的 规律, 存在重形式、轻效果, 增加了体育教 师和学生的负担, 学生参与的热情和积极性 不高, 长此以往必将影响阳光体育运动的可 持续发展。经过多年的实践和研究，我们提 出以下阳光体育运动开展的组织原则和策 划方法, 以供研究者进行探讨和各级管理部 门及学校在阳光体育活动的组织中进行参 考。 


\section{2. 学生阳光体育活动的组织原则}

\section{1 认知培养与习惯养成相结合原则}

青少年对体质健康认知水平的提高, 可 以促进其养成健康的生活方式和与体育锻 炼的习惯。认知的提高是对事物本质认识不 断深刻的结果, 对学生认知能力的培养必须 符合其知识背景和特点, 要多运用实际事例 来启发他们对事物的自我认识, 通过潜移默 化的过程使他们逐步认识体育锻炼原理和 重要性, 逐渐养成体育锻炼的习惯。如可以 通过著名科学家钱伟长是如何从一个体弱 生, 通过刻苦锻炼, 成长为一个运动健将, 以健康的体魄和坚强的意志蜕变成一个为 人民做出突出贡献的科学家; 再如当今总理 温家宝是如何在青年时代健身强体、励志图 强, 由一个平民子弟成长为共和国的总理, 为社会的发展和人民的幸福做出了突出的 贡献。使他们认识到学习工作、事业成功, 以及幸福的生活都离不开健康的身体。对学 生进行健康教育时语言要生动形象, 通俗易 懂, 要避免空洞的说教和泛泛而谈, 使他们 明确健康的含义, 逐步树立 “健康第一” 的 理念, 积极投入阳光体育运动, 通过教育培 养体育兴趣与养成良好的生活习惯, 为自主 运动以及终身体育打下良好的基础。

\section{2 校内校外与课内课外相结合原则}

阳光体育运动要作为一种生活方式贯 穿青少年学生的课内外与校内外, 并将校内 外和课内外进行有机的结合, 即课内学习、 课外锻炼, 校内组织、校外自主。在校内组 织各种活动的基础上, 还要求学生进行校外 的自主锻炼, 提倡学生积极参与青少年体育 俱乐部, 以及社区和家庭等组织的体育活 动, 实现体育生活化。

继续深化教育教学改革, 完善体育课程 设置, 丰富教学内容, 提高体育课程设置的 系统性和科学性。要求各校都要努力拓展体 育课程之外的隐性教学资源, 建立符合本校 特色校本项目。例如上海中医药大学要求每 个学生必须掌握太极拳, 上海第二工业大学 开展健身珴球人人达标活动, 使学生在练习 过程中增强体质。在学生的成长过程中家庭 和家长的也起着重要的作用, 一个家庭的生
活方式和习惯都往往可以影响到一个学生 的一生, 特别是家长的还是学生从小就模仿 学习的对象, 对学生养成良好的习惯起着决 定性的作用。我们可以采用布置家庭作业的 方法, 规定学生在业余时间完成一定的项目 和运动量, 如郊游、晨跑等, 并要求家长监 督或一起参与, 充分发挥家庭在开展阳光体 育活动中应有的作用, 保证学生得到合理膳 食营养, 培养体育锻炼的习惯, 促进学生养 成正确生活方式。

\section{3 因地制宜与突出特色相结合原则}

我国幅员辽阔、民族众多，各地都有一 些独特的民间体育运动项目, 我们在充分利 用校内体育资源的同时,还要重视和挖掘当 地的自然及文化资源, 开展各种适合本校条 件, 学生喜闻乐见、锻炼效果好, 容易组织, 特色鲜明的活动项目。如北方许多城市的已 经成为传统的冬季冰上运动, 既锻炼了学生 的身体素质, 也培养了学生的意志品质; 如 上海浦东三林镇结合当地优势项目在全镇 中小学中开展 “舞龙” 运动, 在提高学生体 质，丰富校园体育文化氛围的同时，也为当 地培养了众多的舞龙高手和爱好者; 再如上 海市为了推进乒乓球运动进校园, 组织开展 了 “千校万班乒乓球赛” , 在上海市中小学 中兴起了人人练习乒乓球的高潮。这些普及 参与程度高特色鲜明的活动形式和内容, 为 开展阳光体育发挥了积极的促进作用。

\section{4 校长重视与教师积极参与相结合原则}

校长是学校阳光体育活动开展的第一 责任人, 离开校长的支持学校的阳光体育运 动就不可能落到实处。每一个合格的校长都 应该是一个教育家, 都要深刻理解和重视体 育在青少年学生成长过程中所发挥的作用, 在当前应试教育横行的大背景下, 如何寻求 学生德智体全面发展, 提高学生的综合素 质, 每一个校长都要勤于思考, 勇于实践, 力求改善我国青少年学生体质健康全面下 滑的窘境。目前, 许多省市都在出台措施, 甚至明确规定校长作为学生体质健康促进 中发挥的作用, 学生体质达标合格与否将成 为考核学校办学成绩的一票否决线, 这无疑 加深了各级学校校长的责任, 在这种新形势 下, 要求作为学校的决策人, 既要认清责任, 
提高认识, 还要深入研究, 制定措施, 努力 把开展学生阳光体育运动落实到实处, 切实 提高学生体质。

教师, 包括班主任以及其他任课教师的 积极参与是促进学生阳光体育活动蓬勃开 展的关键, 阳光体育进校园使学校体育迎来 了又一个发展的机遇, 同时也是我们体育教 师一个拓展知识、提高组织策划能力、提升 在学校地位的绝佳机会, 我们一定要牢牢把 握。由于长此以来受到应试教育的影响, 学 校体育受到的重视程度不高, 体育教师的地 位偏低, 体育教师群体在学校中的发展也受 到种种限制。但是随着我国青少年体质状况 的逐年下降, 学校体育被推倒了风口浪尖, 由党和政府倡导的学生阳光体育活动正是 在这种背景下提出提高学生体质的重要举 措, 正所谓危机也是机遇, 体育教师要将提 高学生体质健康作为自己义不容辞的责任, 努力克服阳光体育进校园所带来种种困难, 深入开展阳光体育运动的研究, 关心爱护每 一个学生, 特别是那些体弱生和所谓的体育 后进生, 加强与校领导以及其它科目教师的 交流沟通, 争取他们的支持和理解, 为阳光 体育进校园提供一个良好的人文环境。

\section{5 面向全体与榜样带动相结合原则}

阳光体育活动的组织要面向全体学生, 目的要让每一个学生都能得到健康的发展。 同时也要注意培养和发挥体育骨干的榜样 作用, 带动身边同学投入体育锻炼。榜样的 力量是无穷的, 我们在感慨姚明现象在青少 年中带来的篮球热, 也依稀记得当年范大将 军所引领的足球潮, 同学们身边的体育小明 星也能够激发他们参与体育锻炼的兴趣。由 于升学的压力, 曾经开展普遍的各级学校课 余运动队训练几乎处在停滞和消失的边缘, 学生的运动能力和运动技术水平也在逐年 下降。一个学校的运动队往往代表着这个学 校的传统和文化以及历史积淀, 也是一个学 校的精神传承, 它所带来的对学生的激励作 用是其他任何项目都无法比拟的。恢复和保 持这种传统对促进学生阳光体育活动的开 展有着积极的促进作用, 应该引起高度重 视。

\section{6 物质基础与制度保障相结合原则}

物质基础包括阳光体育活动开展所需 的场地、器材和运转经费。随着我国教育经 费不断的增加, 学校运动场地、器材, 以及 开展阳光体育运动所必须的经费将会得到 较大的改善。许多学校特别是老少边穷地区 学校多年的欠账将会得到逐步的偿还, 各级 教育管理部门要计划的对所属学校的运动 场地做好规划, 并保证设立阳光体育促进专 项资金, 为学生阳光体育活动进校园保驾护 航。如上海市教委在制定 “十二五教育发展 规划” 中, 将学生体质健康促进作为十大工 程之一，拨付了巨额资金，并根据各级学校 的学生人数和体育活动开展状况下发阳光 体育促进费, 为沪上学校推进学生阳光体育 活动的有序开展起到了主要作用。

建立完善的阳光体育促进制度是活动 是否能够得以可持续发展的保证，包括建立 健全组织机构、设计长效机制与活动方案、 完善检查考核标准等制度体系。制度设计要 注重实用性和实效性, 避免繁杂和虚套, 便 于操作与执行。应该说学生阳光体育活动的 开展物质是基础, 制度是保障, 二者之间相 互制约和促进, 完善二者并有效结合才可以 发挥最大功效。

\section{7 有效性与安全性相结合原则}

活动的组织既要注重形式还要强调效 果, 必须注重实效性和有效性, 活动组织还 要便于操作, 使学生乐于参与, 提高效率。 有效性的前提是安全性, 二者必须紧密结 合。近年来在学校各类体育活动中伤害事故 频发, 特别是一些恶性事故, 如运动猝死等, 给学校体育活动的正常开展蒙上了一层重 重的阴影, 许多学校的采取诸如运动会取消 长跑项目、减小体育课运动量、降低体育课 考试难度等方式来规避学校体育所面临的 风险。凡此种种, 已经引起了教育管理部门 和一些专家学者的关注, 各路媒体也纷纷进 行报道, 一时间给学校阳光体育运动的开展 带来莫名的压力。这就要求我们在每次活动 开展前都要摸清每一个学生的身体状况, 把 握和分化高危人群, 并建立阳光体育活动安 全应急预案, 预防和减少伤害事故的发生。 
2.8 监测训导与健康促进相结合原则

阳光体育活动的目标是提高学生体质 健康水平, 所有学校都要积极开展《国家学 生体质健康标准》的测试, 加强对学生体质 健康状况的监测和训导是阳光体育运动的 重要内容和手段, 其目的是为了掌握学生体 质健康发展的规律, 发现存在的问题, 并根 据监测的结果对学生进行针对性的训练指 导, 增强学生体育锻炼的效果。学校可以利 用现代信息技术和测试设备, 提高体质监测 的效率, 提高数据分析的准确性和及时性。 为学生提供包含运动处方、生活方式建议、 膳食营养指导等全面系统的体质健康促进 方案, 提高阳光体育运动的科学性。

\section{9 校内竞赛与阳光体育联赛相结合原则}

校内竞赛活动安排要系统, 既要有全校 性的运动会、也要有单项比赛、也可以学生 社团为主开展小型多样、丰富多彩的体育比 赛，努力做到 “人人有项目、班班有团队、 月月有竞赛”。在搞好校内竞赛的同时, 还 要注意将校内的竞赛和市区举办的阳光体 育大联赛有机结合, 充分发挥竞赛的杜杆作 用, 提高学生参与阳光体育活动的积极性, 在锻炼中提高体质, 在活动中提高运动水 平。

\subsection{0 考核奖励与总结改进相结合原则}

检查考核的目的是促进, 每个学校都要按要 求建立和完善本校的阳光体育活动检查考 核机制, 以促进各项工作的开展。阳光体育 活动开展的时间还不是很长, 无论是政策制 定, 还是组织方法, 以及学生反应都会有许 多意想不到的问题, 所以要及时总结经验教 训, 改进措施与方法, 提高组织能力, 使阳 光体育活动迈上新的台阶。对在学生阳光体 育活动开展中涌现的先进人物和事迹要及 时表扬与宣传, 以提高参与者的积极性和主 动性。

\section{3. 学生阳光体育活动的组织策略与方法}

阳光体育活动的十项组织原则, 是各级 学校策划活动方案的依据, 组织开展学生阳 光体育活动必须注意以下策略与方法。
3.1 贯彻内涵、完善顶层设计、实现重心下 移

组织方案制定要深入贯彻学生阳光体育运 动的内涵, 把握活动的发展方向, 完善顶层 设计。要以提高学生体质健康水平, 丰富校 园体育文化为目标, 以促使每一个青少年学 生的健康发展为目的。在完善顶层设计的前 提下, 必须将活动的重心下移, 活动方案要 将每一个学生作为落实点, 保证覆盖面和受 益面。学生阳光体育活动的中心是学生, 积 极鼓励学生参与阳光体育活动, 使学生在阳 光沐浴中得到身体的发展, 感受体育带给人 类的健康与快乐。

\section{2 目标明确、切合实际、突出主题创意}

制定学校学生阳光体育活动的策略要 将上级要求与本校实际情况相结合, 提出明 确的合理的目标。阳光体育运动的终极目标 是促进学生的体质健康, 各级学校在设定目 标时要根据本校学生的具体情况, 并针对迫 切需要解决的、比较突出的问题设立切实可 行的改进措施与方案, 目标的设定要可量 化、可测定，并可以划分为一定的层次和阶 段, 分步实施。活动方案要突出主题创意, 并围绕主题创新活动设计, 提高立意, 彰显 活动的思想内涵。

\section{3 突出亮点、体现特色、兼顾内容与形式}

活动的策划要结合本校的特长和优势, 突出活动的亮点, 体现特色。活动内容的选 取要有针对性, 便于长期有效开展。如上海 已经施行多年的学生每人 “一毽、一绳” 和 “人人学会游泳” 等项目的设计将任务和目 标紧密结合, 亮点突出、特色鲜明, 促进了 阳光体育活动的可持续发展。活动形式选择 要注意多样性, 既要突出一定的轰动效应, 更要注意活动形式的有效性, 如在全国多地 学校实行的 “大课间”、“体育节”、“青 少年俱乐部” 等行之有效的举措, 还要注意 发挥社区组织, 以及学生家庭等隐性活动形 式的重要作用, 如建立体育锻炼兴趣小组, 提高青少年参与体育活动的积极性。活动内 容选择与组织设计要统筹兼顾, 以利于既定 目标的实现。 
3.4 全面系统、易于操作、形成完整闭环的 质量监控体系

活动方案的策划要求结构完整, 条理清 晰, 细节完善, 易于操作实施与检查考核。 组织方案策划既要涵盖组织机构设立、场地 器材准备、人员经费落实、活动内容和活动 形式选择、安全预案, 还必须包括评估考核 及总结奖励的方式和方法, 使整个方案有措 施、有落实、有检查、有考核、形成一个能 够完整闭合运行的质量监控体系, 便于及时 找出存在问题和寻找解决措施, 突破发展的 瓶颈, 提高阳光体育活动开展的水平和质 量。

\section{4. 结论与建议}

4. 1 阳光体育运动的开展必须遵循体育运 动的规律, 并牢牢把握活动组织的十项基本 原则。并将其作为组织策划阳光体育活动的 依据。

4.2 校长作为阳光体育活动进校园的第一 责任人必须谨记自己的责任, 体育教师作为 体育运动的倡导者, 要将发展提高学生的体 质健康水平作为己任, 认真研究, 努力实践。

4.3 制定阳光体育活动方案必须要有针对 性和目标，切合本校场地设施、师资力量、 以及学生实际情况, 方案要便于操作和实 施。

4.4 阳光体育活动方案设计要做到内容完 善, 措施得当, 形式合理, 并建立可供闭合 运行的质量监控体系, 搞好总结表彰和奖 励, 促进学生阳光体育运动的可持续发展。

\section{References}

[1]ZHU Fengjun; et al. Research on Management Mechanism of Sports Competition and Relevant Issues in Developed Sports Countries. Journal of Chengdu Sport University. vol.32,pp.111-115,2006.

[2] LIU Haiyuan ; YUAN Guoying. Exploration of several issues about developing the Sunny Sports Movement. Journal of Physical Education.vol.14,pp.10-14,2007.
[3]TANG Jun. Understanding and Ponderation Over Launching of Students Sunshine Sports Activity. Sport Science and Technology. vol.31, pp. 30-33, 2010.

[4] YANG Bin ; PU Yan. Sustainable Development of Family Physical Education and Sunlight Sports Activity.Bulletin of Sport Science \& vol.30,pp.93-94,2010.

Technology.

[5] ZHANG Jie. Establishment of Informational Index System of College Sunny Sports Program.Journal of Wuhan Institute of Physical Education. vol.46,pp.84-86,2012.

[6] ZHAO Chenglei. Analysis on the Choice of Extracurricular Sports under the Plight of Sunny Sports Movement for College Students. Journal of Beijing Sport University. vol.35,pp.88-91,110,2012. 